\title{
Underspecification in the semantics of word formation: the case of denominal verbs of removal in Italian
}

\author{
KLAUS VON HEUSINGER AND CHRISTOPH SCHWARZE
}

\section{Abstract}

This article analyzes a case of Italian word formation in which the semantics of the derived words appears to contain mutually exclusive ambiguities. Italian productively derives verbs of removal from nouns. These verbs have the general semantic form $A$ removes $X$ from $Y$. There are two subtypes that differ in whether the nominal base is taken to be the FIGURE or the GROUND: scremare 'to skim' (crema 'cream') is a FIGURE verb, and scarcerare 'to release from prison' (carcere 'prison') is a GROUND verb. Current analyses are at a loss to give a uniform account for the semantics of derivational processes of these two kinds. In this article, such an analysis is proposed. It is based upon the model of lexical semantics known as twolevel semantics. Two-level semantics makes a distinction between a layer of meaning, which is defined by grammar, and a level of interpretation, which is based upon conceptual knowledge. We propose that the derivation of Italian denominal verbs of removal of both types starts from a single underspecified representation, which is then specified at the conceptual level; depending on the concept type of the base, the denominal verb is either a FIGURE verb or a GROUND verb. This study is an example of how the semantics of language-specific morphology may be embedded in cognitive structure.

\section{Introduction}

In this article $^{1}$ we shall discuss a case of systematic meaning variation that appears in Italian denominal verbs of removal (henceforth DVRs). We can distinguish two subtypes of DVRs, FIGURE verbs and GROUND verbs, ${ }^{2}$ as listed in (1) and (2): 
(1) FIGURE verbs

sbucciare 'to peel' cf. buccia 'peel'

scremare 'to skim' cf. crema 'cream'

sfasciare 'to unbandage' cf. fascia 'strip, bandage'

sfollare 'to evacuate' cf. folla 'crowd'

spennare 'to pluck' cf. penna 'feather'

(2) GROUND verbs

sbarcare 'to unload; to disembark' cf. barca 'boat'

scarcerare 'to release (from prison)' cf. carcere 'prison'

scardinare 'to take off its hinges' cf. cardine 'hinge'

sfornare 'to take out of the oven' cf. forno 'oven'

sganciare 'to unhook; to unfasten' cf. gancio 'hook'

Both types of DVRs refer to events of caused removal of an object $\mathrm{X}$ from another object Y. Thus, DVRs can be assigned the general semantic structure $A$ removes FIGURE $X$ from GROUND $Y$. The two subtypes differ in the way the two locative arguments FIGURE and GROUND are filled by the nominal base. In FIGURE verbs, the nominal base fills the FIGURE argument (cf. scremare 'to remove the cream from something') and in GROUND verbs, it fills the GROUND argument (cf. scarcerare 'to release someone from prison'). The question is whether we can account for both types of DVRs with one derivational process, or whether we have to assume two processes. The latter choice has been taken and elaborated, for German DVRs, by Stiebels and Wunderlich (1995). These authors postulate two different elementary predicates for the two groups, FIGURE verbs, and GROUND verbs. In this article, we are proposing a stronger hypothesis. In fact, we argue that one underspecified derivational process can account for the two subtypes and that the difference between the subtypes is only spelled out at the conceptual level. This treatment is motivated by the observation that the concept type of the base determines to which subtype a given DVR belongs.

The $s$-prefixed DVRs of Italian are a good example of how conceptually based polysemy is restricted by the grammar of a particular language, and they constitute a clear-cut subclass of denominal verbs. In more general terms, we aim at contributing to a better understanding of systematic meaning variations in word formation.

The article is organized as follows: In the first part (Section 1), we discuss some general assumptions that underlie this study. We give a descriptive account of Italian DVRs (Section 2) and propose a morphological rule that generates them with an underspecified semantics (Sections 3 and 4). We finally discuss the problem of how this underspecification is resolved (Section 5). 


\section{Four basic assumptions}

This study is based upon four basic assumptions, namely, that lexical morphology is an autonomous subsystem of grammar, that it defines forms as well as meanings, that lexical meaning is organized at two connected levels, and that semantic representations may be underspecified.

\subsection{Derivational morphology as a generative subsystem of grammar}

The first assumption is that lexical morphology can be represented in terms of rules that generate words and assign them an internal structure as well as certain grammatical properties. Regardless of the format of these rules, they must specify constraints on their input and on their output. Furthermore, there must be a lexical inventory of morphological segments, described in such a way that they can be matched with the constraints. ${ }^{3}$ We will use a format of morphological representation that combines semantic with functional representations of the kind proposed in Schwarze (1999).

\subsection{The semantics of derived words in lexical morphology}

The second assumption is that the rules of lexical morphology not only define derived word forms and their syntactic properties, but also novel lexical meanings. These rules operate on morphological segments as well as on their semantic representations. To illustrate this by a deverbal verb: the rule that in Italian defines verbs such as sconnettere 'disconnect', applies to both a basic morphological segment (connett-) and its meaning. The base or root is represented by (3a) and the prefixed verb stem by (3b):

(3a) i. connett-, $\mathrm{v}$

ii. PRED $=$ 'CONNETTERE (SUBJECT, DIRECT_OBJECT, OBLIQUE ${ }_{\text {WITH }}$ '

iii. SUBJECT : $\mathrm{x}$, DIRECT_OBJECT: $\mathrm{y}$, OBLIQUE $_{\mathrm{WITH}}: \mathrm{z}$

iv. $\lambda \mathrm{z} \lambda \mathrm{y} \lambda \mathrm{x}$ CAUSE $(\mathrm{x}, \operatorname{BECOME}(\operatorname{CONNECTED}(\mathrm{y}, \mathrm{z}))$

(3b) i. $\quad\left[\mathrm{s}-\mathrm{v}\right.$-prefix $\left.[\text { connett }-]_{\mathrm{v}}\right], \mathrm{v}$

ii. $\quad$ PRED $=$ 'SCONNETTERE (SUBJECT, DIRECT_OBJECT, OBLIQUE FROM $_{\text {) }}$ '

iii. SUBJECT : $\mathrm{x}$, DIRECT_OBJECT: $\mathrm{y}$, OBLIQUE $_{\mathrm{FROM}}: \mathrm{z}$

iv. $\lambda \mathrm{z} \lambda \mathrm{y} \lambda \mathrm{x}$ CAUSE $(\mathrm{x}, \operatorname{BECOME}(\neg \operatorname{CONNECTED}(\mathrm{y}, \mathrm{z}))$ )

In both representations, ${ }^{4}$ line i. gives the (simple or complex) form and its lexical category. ${ }^{5}$ Line ii. contains a functional description in the format 
of Lexical Functional Grammar (LFG); according to that format, subcategorization is expressed in terms of grammatical functions. (The arrow notation, which is used in LFG to express the structure-building functions, is omitted here for the sake of simplicity.) Line iii. represents the mapping of the grammatical functions onto the arguments contained in the semantic representation. Line iv. gives the semantic representation with the linking mechanism by lambda abstraction.

In general, it is not always easy to discover and formulate the rules of lexical morphology, and even more so regarding their semantic component. This difficulty is due, to a large extent, to lexicalization. Every rule of word formation feeds the supply of mentally stored lexical items, and lexicalized derived words may have their own semantic evolution, in such a way that they are no longer analyzable within the generative system. They may, however, still be analyzable by virtue of general rules of polysemy, which indistinctly apply to derived and simple words. As an example, take the meanings of the English word kindness:

(4) kindness

a. 'the state or quality of being kind'

b. 'a kind act, a favor'

Only meaning a. is defined by a morphological rule; meaning $b$. is derived from meaning a. by a rule of polysemy, which can tentatively be formulated as (5):

(5) $\mathrm{P}_{1}$ quality $\rightarrow \mathrm{P}_{2}$ action characterized by $\mathrm{P}_{1}$

Processes of this kind create data that cannot be accounted for in lexical morphology.

A similar difficulty arises from the interplay of morphological change and lexical storage. When a rule of word formation changes or disappears from the generative system, the lexicalized words it created are still present in the lexicon and may stay there for a long time, in such a way that they leave fossilized, recurrent structures that are mere patterns. The English "prefix" a-, as in (6), seems to be such a case:

(6) abroad, abreast, across, adrift, afloat, afoot, alike, anew, ashore, away

The rule that derived these words has disappeared from the grammar of English. A similar case is the Italian suffix -accio, which in modern Standard Italian means 'bad' or 'ugly', as in (7), but in the past meant 'big' a reading that is still present in various lexicalized nouns, be it in combination with the idea of badness, as in (8), or without it, as in (9): 
(7) tempaccio 'bad weather'

(8) coltellaccio 'big, dangerous knife'

(9) colombaccio 'a kind of big wild pigeon' cf. tempo 'weather'

cf. coltello 'knife'

cf. colombo 'pigeon'

These diachronic processes, combined with lexicalization, have brought about polysemies that are not systematic, and which speakers must learn as idiosyncrasies. Difficulties like these certainly have contributed to the fact that the semantics of word formation has not been considered an attractive field of investigation by semanticists. But they can be overcome if an adequate conception of the lexicon and lexical processes is available.

\subsection{Lexical meaning, polysemy and two-level semantics}

The term polysemy is often used in a loose, descriptive sense, and specific theories of polysemy explore various aspects of the phenomena covered by this term. One of these theories is the hypothesis of two-level semantics, which was first formulated by Bierwisch $(1982,1983)$. It claims that word meanings have two strata: the semantic stratum, which is part of the grammatical structure of the language, and the conceptual stratum, which belongs to the more general cognitive system of the speakers. At the semantic level, representations of lexical meaning are monosemous. They integrate lexical semantics into the compositional semantics of the sentence, and they are mapped onto syntactic structure via the lambdacalculus or some other device. At the conceptual level, the semantic representation is linked to a central concept.

After its first formulation, two-level semantics was further elaborated (see e.g., the contributions in Bierwisch and Bosch 1995) and it was also applied to the semantics of word formation (Mayo et al. 1995; Schwarze 1995; Stiebels and Wunderlich 1995; Stiebels 1997; Wunderlich 1997). Pause et al. (1995) and Schwarze and Schepping (1995) applied this approach to problems of polysemy. In Pause's conception, the semantic representation of a polysemous word contains a core meaning and its various readings. These readings are derived by rules of usage, which refer to the conceptual stratum (Pause et al. 1995: 279). Schwarze and Schepping (1995) share the position that variation of lexical meaning can be represented via a core meaning and its conceptually induced variants. Looking at examples of crosslinguistic variation of polysemy, they confirm the hypothesis that conceptual structure as such does not trigger, but only motivates polysemy. The present article will address the question of how the organization of lexical meaning, as hypothesized in the two-level approach, interacts with underspecification. 


\subsection{Lexical underspecification}

In phonology, a lexical representation is underspecified if it leaves a feature open to be specified on the basis of contextual information during the derivation. An example is Italian $/ \mathrm{n} /$, whose place of articulation is not lexically specified: in surface representations, $/ \mathrm{n} /$ is dental, labial, or velar; cf. the variation of It. un ' $a$ ' in (10):

$$
\begin{aligned}
& \text { dental /n/: [un'ni:do] un nido 'a nest' } \\
& \text { labial /n/: [um'ba:tjo] un bacio 'a kiss' } \\
& \text { velar /n/: [un'ka:ne] un cane 'a dog' }
\end{aligned}
$$

The underspecified feature becomes specified as labial before a labial, as velar before a velar, and as dental elsewhere. Lexical $/ \mathrm{m} /$ differs from $/ \mathrm{n} /$ inasmuch as its place of articulation is not underspecified: $/ \mathrm{m} /$ is labial by definition.

We can use the notion of underspecification in lexical morphology in exactly the same way. A lexical representation is underspecified if one or more features are left open at the stage of semantic representation, but must be specified at some point of the derivation.

Notice that lexical underspecification is different from vagueness. An underspecified feature must at some point become specified; otherwise the word cannot be used in an utterance, whereas a vague meaning may be left open in an utterance. As an example, take the difference between a noun with a vague meaning, such as vehicle, as opposed to Italian denominal nouns with the suffix -aio. Italian nouns derived with -aio, in order to be used, need a meaning component that cannot be defined by a derivational rule, unless one postulates a specific rule for each possible meaning; cf.:

(11) giornale 'newspaper' + -aio $\rightarrow$ giornalaio 'a newspaper vendor'

(12) vespa 'wasp' + -aio $\rightarrow$ vespaio 'a wasps' nest'

(13) rottame 'scrap' + -aio $\rightarrow$ rottamaio

a. 'a person who trades in scrap'

b. 'a junk yard'

As these examples show, denominal nouns suffixed with -aio may refer to persons, as in (11), or to places, as in (12), or to both, as in (13). The lexical properties of the suffix leave the categorization open. But when the derived nouns are used, the category must be specified: speakers must know whether the referent is a person or a place. Such a specification is not required for a vague noun like vehicle; that noun may successfully be used without any further information, as demonstrated by (14): 
(14) The museum exhibits all kinds of vehicles.

Semantic underspecification also is distinct from semantic ambiguity. An ambiguous word has more than one semantic representation, and the resolution of ambiguity picks out one of them. An underspecified word, on the contrary, has just one incomplete semantic representation, and the resolution of underspecification is the completion of that representation.

In the remainder of this study we investigate a particular class of Italian denominal verbs from the following perspectives: i. lexical morphology as an autonomous subsystem of grammar; ii. the morphological derivation of forms as well as of meanings; iii. the organization of lexical meaning at two connected levels; and iv. the underspecification of semantic representations.

\section{Descriptive analysis of Italian denominal verbs of removal}

Italian denominal verbs of removal (DVRs) with prefix $s$ - are a subclass of denominal verbs (DVs). In general, DVs are underspecified with respect to the role of the base in the situation they describe. They are classified dependent on that role, such as instrument, source, goal, and theme. The specification of that role may almost exclusively rest upon conceptual knowledge. But there may be prefixes that restrict the range of possible specifications. If, in that case, the prefix does not entirely determine the specification, the process of word formation raises an interesting question regarding the interface between semantics as a component of grammar and conceptual structure as a component of general cognition: how do semantic and conceptual structure interact in the construction of lexical meaning? This problem can best be studied if the options left open by the prefix are just two; one can expect that in such a case the interface mechanisms will be best observable. Italian DVRs are such a case. They are well represented in the lexically stored vocabulary (for a small selection of DVRs see the Appendix). The rule that underlies these forms has been productive for centuries and still is: native speakers can use and understand novel verbs of the DVR type. ${ }^{6}$

The roots of DVRs are derived from nouns by conversion, i.e., there is no derivational suffix. (The vowel $-a$-, which follows the roots in most cells of the paradigm of DVRs is a stem extension. It does not turn nouns into verbs. On the contrary, it requires that the root be a verb root.) The prefix $s$ - has, loosely speaking, a negative meaning. For convenience, we give the derivation for scremare and stanare in (15): 
a. crem-a 'cream' $\rightarrow$ s-crem-are 'to skim'

b. tan-a 'burrow' $\rightarrow s$-tan-are 'to remove from the burrow'.

Syntactically, most DVRs are transitive; i.e., they govern two grammatical functions, a subject and a direct object. If the verb is a GROUND verb, as in (15b), an oblique with the preposition $d a$ 'off' may be added. Semantically, DVRs refer to events of caused motion. As has been shown above, they fall into two types, according to whether the verb stem encodes, in terms of Talmy (1985), the FIGURE or the GROUND. The term FIGURE refers to an object or a substance that can easily be moved, while GROUND refers to an object or place that is not easily movable, but fixed to its position. In the one type, the FIGURE verbs, the verb stem lexicalizes the (movable) FIGURE, and the direct object is GROUND, as in scremare 'to remove the cream from X'. In the other type, the GROUND verbs, the verb stem lexicalizes the (fixed) GROUND, and the direct object is the movable FIGURE, as in stanare 'to remove from the burrow'. ${ }^{7}$

The following tables summarize the descriptive analysis: (16) describes the general structure of all denominal verbs, while (17) and (18) show the particular patterns for FIGURE verbs and GROUND verbs, respectively:

(16) All denominal verbs of removal:

Motion: caused

PATH: the FIGURE moves away from the GROUND

MANNER: not specified

Mapping onto syntax: open

(17) FIGURE verbs:

sbucciare 'to peel' (buccia 'peel')

sfasciare 'to unbandage' ( fascia 'strip')

Mapping on syntax:

FIGURE: verb stem

GROUND: direct object

(18) GROUND verbs:

snidare 'to drive out from a hiding place' (nido 'nest')

sbarcare 'to unload, to disembark' (barca 'boat')

Mapping onto syntax:

FIGURE: direct object

GROUND: verb stem

Among the lexicalized, transparent DVRs, there seem to be more FIGURE verbs than GROUND verbs. Among the 64 verbs listed in the Appendix, there are 40 FIGURE verbs, 20 GROUND verbs, and 4 verbs that can receive both interpretations. ${ }^{8}$ One of the latter is scartare, derived from carta 'paper'. In fact, in a phrase like (19) the verb stem may be understood as lexicalizing either the FIGURE or the GROUND: 
(19) scartare il regalo 'un-paper the gift'

a. 'to remove THE PAPER from the gift' (FIGURE verb)

b. 'to take the gift OUT OF THE PAPER' (GROUND verb)

In this example, however, there is a sort of conversion, with no effect on truth conditions. It may thus be concluded that there is virtually no ambiguity between the FIGURE and the GROUND reading in the given context. The examination of the corpus of lexicalized forms has shown another descriptive fact: Typically, FIGURE and GROUND are concrete objects or substances, and MOTION is spatial. This applies to all examples given up to now. But both may be abstract as well; cf.:

(20) fame 'hunger' $\rightarrow$ sfamare 'to appease someone's hunger' brama 'longing' $\rightarrow$ sbramare 'to appease someone's longing' colpa 'guilt' $\rightarrow$ scolpare 'to prove someone's innocence'

This is the consequence of a general rule of polysemy, according to which terms referring to spatial motion may also refer to changes of abstract states. The component 'to take away', which is characteristic of DVRs, undergoes the same process. It is interesting to see that not the DVR as such, but one of its meaning components is responsible for this polysemy.

Another kind of meaning variation concerns abstract FIGURES. Some FIGURE verbs, in fact, do not refer to the separation of two entities, but to a situation where only the GROUND is an entity, the FIGURE being a quality which is stripped from that entity; cf.:

(21) chiesa 'church' $\rightarrow$ schiesare 'to cancel the quality of being a church' dottore 'doctor' $\rightarrow$ sdottorare 'to deprive someone of the title of doctor'

vergine 'virgin' $\rightarrow$ sverginare 'to deflower'

Again, this meaning variation (treating a quality as an object) does not concern the verbs as such, but only components of their meanings.

\section{Morphological analysis}

Regarding morphological constituent structure, the question is whether DVRs are directly derived from nouns (22a), or whether an intermediate stage must be assumed, with an unprefixed denominal verb, which then, in turn, is prefixed in a separate process; see (22):
a. $\quad \mathrm{N} \rightarrow$ CONVERSION \& PREFIXATION $s$-V
b. $\quad \mathrm{N} \rightarrow{ }_{\text {CONVERSION }} \mathrm{V} \rightarrow$ PREFIXATION $s$ - $\mathrm{V}^{9}$ 
Notice that (22a) is meant to express that the conversion from noun to verb and the addition of the prefix are two processes which are collapsed into one single rule of word formation. It does not imply that the prefix is responsible for the conversion. Prefixes, at least in Italian, never change their bases' lexical categories.

There is a strong argument in favor of the longer chain. The reader will remember the deverbal verbs of reversal mentioned above, cf. the analysis of It. sconnettere (3b). The longer chain of derivation yields a unitary treatment DVRs "plain $s$-verbs" like sconnettere. ${ }^{10}$

Obviously, a derivation of DVRs along the lines of (22b) requires that the intermediate unprefixed denominal verb be of the same semantic type as the underived verbs that constitute the input to $s$-prefixation. Consider again It. sconnettere. This verb denotes a reversal that involves two states, $s_{1}$ and $s_{2}$. State $s_{1}$ is the result of an event denoted by the input verb; state $s_{2}$ is brought about by the event of reversal, and is described as the negation of $s_{1}$. Hence the intermediate denominal verbs postulated by the longer chain of derivation must denote the creation of a state. And, if $s_{2}$ is a state of location, then $s_{1}$ must be too. In other words: The intermediate verbs must denote events by which some object is located with respect to another object, denoted by the original noun.

For example, for scremare 'to remove the cream' a verb cremare is postulated, which must mean 'to bring about the presence of cream'. Likewise, for stanare, hypothetical tanare must mean 'to put into a burrow'; cf. (23) and (24) respectively:

(23) (hypothetical) cremare $\lambda \mathrm{z} \lambda \mathrm{y} \lambda \mathrm{x}$ [CAUSe (x, BeCOMe (LOCATED $(\mathrm{y}, \mathrm{z}))) \&$ CREMa $(\mathrm{y})]$

(24) (hypothetical) tanare $\lambda \mathrm{z} \lambda \mathrm{y} \lambda \mathrm{x}$ [CAuse (x, BeCome (LOCATED $(\mathrm{y}, \mathrm{z}))) \&$ TANa $(\mathrm{z})]$

To evaluate the hypothesis, two questions can be asked:

i. Are there lexicalized examples of these kinds of verbs?

ii. Is the semantics attributed to the hypothetical verbs reasonable?

The first of these questions can be answered positively for the FIGURE verbs. Italian does have lexicalized verbs of this type:

$$
\begin{aligned}
& \text { acqua 'water' } \rightarrow \text { acquare 'to water' } \\
& \text { sale 'salt' } \rightarrow \text { salare 'to salt' } \\
& \text { sella 'saddle' } \rightarrow \text { sellare 'to saddle' }
\end{aligned}
$$

Notice, however, that Italian does not present the abundance that English shows in this domain of the lexicon (to butter, to oil, to water etc.), and that words like those in (25) do not seem to have a high rank in usage. 
The normal verb for to water is not acquare, but annaffiare; to butter or to oil do not have literal equivalents in Italian: the translation of to oil is $l u$ brificare, and the translation of to butter is prefixed imburrare.

For the GROUND verbs, such as the hypothetical tanare, (cf. Engl. to bottle, to frame) the situation is similar. There are a few lexicalized verbs of this kind, but they generally have a prefixed variant, which is preferred in usage (26), and most equivalents of English GROUND verbs only show the prefixed variant (27): ${ }^{11}$

(26) cornice 'frame' $\rightarrow$ corniciare, in-corniciare (preferred) 'to frame'

carcere 'jail' $\rightarrow$ carcerare, in-carcerare (preferred) 'to jail'

(27) bottiglia 'bottle' $\rightarrow$ im-bottigliare 'to bottle'

scatola 'can' $\rightarrow$ in-scatolare 'to can'

sacco 'sack' $\rightarrow$ in-saccare 'to sack'

tasca 'pocket' $\rightarrow$ in-tascare 'to pocket'

Admittedly, the fact that lexicalized denominal verbs of location are marginal in Italian yields no strong argument against the derivation of DVRs via intermediate unprefixed verbs. In fact, in any model of generative morphology, rules may create far more derived words than are lexicalized. But one still may want to express the pervasive preference in Italian for prefixed denominal verbs, as opposed to unprefixed ones, and one could do so by skipping the intermediate step in the derivation of DVRs.

Regarding the semantic criterion, the type of semantics exemplified in (23) and (24) raises a problem when the verb refers to a natural kind in such a way that the FIGURE is a part of the GROUND. Consider the hypothetical intermediate verbs capare and costolare (28):

(28) capo 'head' $\rightarrow$ (hypothetical) capare 'to put a head on it';

(hypothetical) capare $\rightarrow$ scapare 'to remove the head' costola 'rib' $\rightarrow$ (hypothetical) costolare 'to put ribs into';

(hypothetical) costolare $\rightarrow$ scostolare 'to remove the ribs'

The hypothetical intermediate verb, having the locative type of meaning described above, contains the presupposition that there is an initial state, in which the individual affected by the action had no head or no ribs, and that the property of having a head or ribs is brought about by some agent. The oddity of that presupposition may possibly be regarded as an argument against the intermediate verb hypothesis. But the presupposition does not need to be evaluated by the speakers, since the intermediate verb is never used. On the other hand, the alternative of deriving DVRs directly from nouns does not raise any semantic problems of this kind, because there is no presupposition about the origin of the initial location. 
So the alternative between the short and the longer derivation of DVRs probably cannot be decided by undefeatable arguments within the scope of our analysis. Since both make the same predictions, one will only prefer the short solution if the long one generates unnecessary derivational complexity. We suspect that Italian DVRs are such a case. But the question of whether logically distinguishable changes are to be accounted for by as many distinct rules implies methodological and, possibly, typological problems that would require a separate study. For the time being, we provisionally prefer the short derivation, because it seems to better fit the Italian data.

We can now proceed to formulating the rule that derives DVRs according to $\left(22 \mathrm{a}^{\prime}\right)$ :

$$
\text { a.' } \quad \mathrm{N} \rightarrow \text { Conversion \& PREFixation } s-\mathrm{V}
$$

This rule, written in the notation borrowed from LFG, which has been introduced above, is given as (29). The following notational conventions are being used. The arrows are functions that project features. The upward arrow ( $\uparrow$ ) projects features up to the mother node. Accordingly, the features INFL_CLASS = ARE ("the derived verbs belong to the class whose infinitive is formed with -are"), SUBJECT ("the verb governs a subject") and DIRECT_OBJECT ("the verb governs a direct object") are projected to node $v$. The downward arrow $(\downarrow)$ points to those features that have already been associated with the daughter node, be it by lexical stipulation or by some process. (For an introduction to the model cf. Bresnan 2001: Chapters 4-6; for its extension to morphology, cf. Mayo et al. 1995; Schwarze 1999; Mayo 1999.)

In our rule, the equation $(\uparrow=\downarrow)$ projects at node $v$ the features already associated with $v$-prefix and $n$ respectively. Notice that the semantic part of the rule is lacking; it will be elaborated in the following sections. ${ }^{12}$

$$
\begin{aligned}
\mathrm{v} \rightarrow \quad \text { v-prefix } & \mathrm{n} \\
\uparrow=\downarrow & \uparrow=\downarrow \\
& (\uparrow \text { INFL_CLASS })=\text { ARE } \\
& (\uparrow \text { SUBJECT }) \\
& (\uparrow \text { DIRECT_OBJECT })
\end{aligned}
$$

The rule states the following: a. there are verbs $(v)$ that are derived from nouns $(n)$ by conversion, ${ }^{13} \mathrm{~b}$. the derived verbs have a prefix, typical of verbs (v-prefix), c. the prefixes and the nouns project their lexically encoded features (including their lexical meaning) to the verbs created by the rule, $d$. the derived verbs belong to the first inflectional class (ARE) and govern a SUBJECT and a DIRECT OBJECT. ${ }^{14}$ 
In (29), that information also contains a feature that encodes the lexical meaning of the noun. The rule does not explicitly state that some of the information lexically associated with the base noun (gender, nominal inflectional class) is discarded.

\section{The semantic representation of denominal verbs of removal}

\subsection{The role of conceptual structure in spatial expressions}

The choice between a FIGURE verb and a GROUND verb results from the conceptual knowledge that the speakers have of the base noun, of the direct object, and of the relationships between both (Mayo 1999: 140141). Speakers actually have the ability to decide, for pairs of objects that are located with respect to each other, which is the FIGURE and which is the GROUND. The effects of this ability can easily be observed in the use of converse spatial prepositions; cf. (30) and (31):

(30) a. The car is in front of the supermarket.

b. The supermarket is behind the car.

(31) a. The bird is on the fence.

b. The fence is under the bird.

Only under very special circumstances would one use the b. sentences. This is explainable by the semantics of spatial prepositions and by a principle of conceptual structure. Spatial prepositions imply that the noun phrase they govern is the GROUND. And there is a principle of conceptual structure that assigns the types of FIGURE and GROUND:

(32) If objects $x$ and $y$ are located with respect to each other, and object $x$ is more salient and more mobile than $y$, then $x$ is the FIGURE and $y$ the GROUND.

Of course, there are more principles of this kind, such as:

(33) If objects $x$ and $y$ are located with respect to each other, and object $x$ is a part of $y$, then $x$ is the FIGURE and $y$ the GROUND.

But is it necessary, in the case of DVRs, to compare, case by case, the two objects involved in the location? Such an intricate model of lexical specification should be avoided for two reasons.

First, the example of spatial prepositions concerns the faculty of discourse production, not the generative system of word formation. There is no need to generalize from one to the other. 
Second, postulating that the meaning of DVRs can only be completed when the direct object is lexically filled, is in contradiction with lexical integrity, and more specifically, with the notion of underspecification, as defined above. In other words, if the full specification of the meaning only took place after the direct object is lexically filled, the resolution of the type assignment would take place at the level of the sentence, and, if the direct object is a personal pronoun, at the level of the text. In this case, the treatment in terms of underspecification would turn out to be inadequate. The kind of resolution which takes place at the sentence and text level is disambiguation; hence we would have to analyze DVRs not as underspecified, but as ambiguous (see discussion below). The assumption that the relation between the object and the base noun determines the type of denominal verb also raises problems for the syntactic approach of Hale and Keyser (1992) or the lexical approach of Wunderlich (1997), Stiebels $(1997,1998)$ or Kiparsky (1997). It would force such approaches to check the relation between the objects involved before the derivation can take place.

We assume rather that the type of denominal verb is determined by the conceptual type (or the conceptualization) of the referent of the base noun. This is an old observation, which was formulated in different ways. Clark and Clark (1979: 791-792) assume that bases for denominal verbs (their "parent nouns") can be classified according to their predominant features roughly as follows:

(a) Placeables:

The parent nouns of locatum verbs denote placeables - things whose conventional role is to be placed with respect to other objects. $[\ldots]$

(b) Places:

For location verbs, the parent nouns denote places - things with respect to which other objects are conventionally placed.

Their placeables (FIGUREs) are the bases for locatum verbs (FIGURE verbs), and places (GROUNDS) are the bases for location verbs (GROUND verbs). Kiparsky (1997: 482) assumes that the "canonical use of" the base determines the kind of denominal verb. Stiebels (1998: 273) reports that the choice of one of the two (or more) abstract verbs depends on the "stereotype properties of the nominal referents". However, there are cases where the base either does not provide a predominant conceptual feature or it provides two possible conceptual features, such as the noun shelf, resulting in two denominal verbs. If we conceptualize the noun shelf as a FIGURE the resulting verb to shelve means 'to provide something with shelves'. If we conceptualize it as GROUND, then the derived verb means 
'to put something on shelves' (cf. the discussion of the Italian verb scartare in example [19] above). These are clear cases of ambiguity which can only be resolved at the level of syntax or discourse, i.e., as soon as we can access the meaning of the direct object in particular and the context in general. However, we assume that we can assign to most base nouns one conceptualization, either as FIGURE or as GROUND.

A short survey of our 64 lexicalized DVRs in Italian (see Appendix) confirms our assumptions. In this representative sample, we find 40 FIGURE verbs and 20 GROUND verbs and only 4 ambiguous cases. The conceptualization of an entity as FIGURE generally corresponds to its (predominant) concept types PART (OF) or SUBSTANCE, as in (34). We conceptualize an object as PART (OF) if it is an (essential) part of a larger object and if it can also be experienced as an independent object and if it can be separated from the larger object by certain events. This fits the characterization of FIGURE or "placeables" of Clark and Clark (1979). An example from our sample is foglia 'leaf', which is the base to the FIGURE verb sfogliare 'to pluck the petals off'. The concepts BODY PART and ATTRIBUTE are subtypes of PART (OF), and base nouns of theses types both lead to FIGURE verbs, such as scostolare 'to remove the ribs' from costola 'rib', and scoraggiare 'to discourage' from coraggio 'courage'. The second basic type for FIGURE verbs is SUBSTANCE, such as grasso 'fat, grease' from which we can derive sgrassare 'to remove the grease from'. ${ }^{15}$

(34) FIGURE verbs and concept TYPE

sfogliare 'to pluck the petals off'; cf. foglia 'leaf'

spennare 'to pluck'; cf. penna 'feather'

PART OF

scostolare 'to remove the ribs'; cf. costola 'rib' BODY PART

scoraggiare 'to discourage'; cf. coraggio 'courage' BODY PART sgrassare 'to remove the grease from'; cf. grasso 'fat, grease'

ATTRIBUTE

SUBSTANCE

The conceptualizations as CONTAINER and PLACE correspond to GROUND, i.e., less movable objects with respect to which other objects (the FIGUREs) are moved. Carcere 'prison' has the predominant feature of being a CONTAINER and the derived verb scarcerare 'to release (from prison)' is clearly a GROUND verb. The conceptualization as PLACE has a local as well as a metaphorical dimension, as in slogare 'to sprain, to dislocate' from luogo 'place', and stonare 'to sing, play out of tune' from tono 'tone'.

(35) GROUND verbs and concept TYPE

scarcerare 'to release (from prison)'; cf. carcere CONTAINER 'prison'

slogare 'to sprain, to dislocate'; cf. luogo 'place' PLACE

stonare 'to sing, play out of tune'; cf. tono 'tone' PLACE 
There are a few nominals that can be conceptualized either way. Carta 'paper' can either be understood as CONTAINER or as PART (OF), yielding a derived verb scartare 'to take off the paper' or 'to unwrap' being a GROUND or a FIGURE verb, respectively. The difference, however, is in this case of a perspectival nature. Both meanings describe the same situation of taking something out of the paper or removing the paper from something, but the emphasis lies in a different point of view. For other bases we find a stronger ambiguity. Filo 'string' can be either conceptualized as SUBSTANCE or as SUPPORT (in a rather wide sense), such that the derived sfilare is either a FIGURE verb ('pull the threads out of, to unstring') or a GROUND verb ('to take from a string'). ${ }^{16}$

(36) FIGURE and GROUND verbs from the same nominal base Scartare, from carta 'paper'

(i) 'to take off the paper'

PART (OF)

(ii) 'to unwrap' CONTAINER

Sfilare, from filo 'string, thread, yarn'

(i) 'to pull the threads out of, to unstring' SUBSTANCE

(ii) 'to take from a string' SUPPORT

We can conclude that DVRs derived from nouns belonging to PLACE, CONTAINER or SUPPORT are liable to be GROUND verbs, and that those derived from the concept types PART and SUBSTANCE are liable to be FIGURE verbs. Some nouns give rise to different conceptualizations and belong therefore to different concept types. In this case, the DVR is ambiguous and the resolution depends on semantic information in the whole sentence, as long as the derived verb is not lexicalized.

\subsection{The semantic representation of DVRs}

Semantically, all DVRs imply the same predicate, which is three-place. (We systematically drop the referential argument $s$ of verbs):

REMOVE $(\mathrm{x}, \mathrm{y}, \mathrm{z})$

In order to represent the semantics of DVRs, the predicate REMOVE must be decomposed. It implies a caused change of state, and the state describes a locative relation between two objects. The semantic predicate CAUSE requires an agent that causes the change of state. The predicate BECOME presupposes (or implies) that the resulting state is the negation of the previous state, namely $\operatorname{LOCATED}(\mathrm{y}, \mathrm{z})$. The semantic predicate LOCATED stands for a locative relation, such as ON, IN, AT, AROUND, between a FIGURE and a GROUND. Thus (37) can be decomposed as the semantic structure (38) or the conceptual structure (39). The AGENT $x$ causes a state in which the 
FIGURE $y$ becomes dislocated from the GROUND $z$. It is presupposed that the FIGURE $y$ was located on the GROUND $z$ in the previous state. ${ }^{17}$

(38) CAUSE (x, BECOME ( $\neg$ LOCATED $(\mathrm{y}, \mathrm{z})))^{18}$

(39) CAUSE $\left(x_{\text {AGENT }}\right.$, BECOME ( $\neg$ LOCATED $\left.\left(y_{\text {FiGURE }}, z_{\text {GROUND }}\right)\right)$ )

Notice that (38) only decomposes the predicate REMOVE; it does not represent the specific meanings of the denominal DVRs, which, as has been shown above, convey information about either the FIGURE or the GROUND which participate in the event of removal.

\subsection{The derived predicate}

Let us now assume, in accord with Section 1.2, that morphological segments have lexical entries, just as words do. Then, again in the notation of LFG, the lexical entry for prefix $s$ - is (40): ${ }^{19}$

(40) $s$-, v-prefix

$$
(\uparrow \text { DPRED })=\text { DIS }
$$

The attribute DPRED ("derived predicate") is distinct from PRED ("normal predicate") inasmuch as it cannot be projected from morphological structure to syntactic structure. A new predicate, with a new argument structure, must be derived before lexical insertion takes place (Mayo et al. 1995: 932; Mayo 1999: 183). The values of DPRED are used to create new predicates, with their lexical meaning and their arguments.

The verbs in whose functional structure the feature ( $\uparrow$ DPRED) $=$ DIS is included have a reversative meaning. The states involved in the reversal are straightforward in the deverbal verbs. They are computed from the verbs' meanings. If the verb is denominal, the states involved are local relationships. This can neither be computed from the prefix nor from the base; it is the rule as such that introduces that component of meaning (just like it introduces other information that cannot come from the constituents, namely the governed grammatical functions and the inflectional class of the derived verb).

But the rule does not define the local relationships; it merely constrains them in such a way that the derived verbs are FIGURE verbs or GROUND verbs. If the predicate $\mathrm{N}$ expressed by the base noun is conceptualized as a FIGURE type, the derived verb is a FIGURE verb and the predicate $\mathrm{N}$ modifies the first argument of the predicate LOCATED, as in (41). If the predicate $\mathrm{N}$ is conceptualized as a GROUND type, the derived verb is a GROUND verb, and the predicate $\mathrm{N}$ is associated with the second argument of the predicate LOCATED, as in (42): 
(41) The meaning of FIGURE verbs (type: scremare) CAUSE (x, BECOME ( $\neg$ LOCATED $(\mathrm{y}, \mathrm{z}))$ ) \& N(y)

(42) The meaning of GROUND verbs (type: stanare) CAUSE (x, BECOME $(\neg \operatorname{LOCATED}(\mathrm{y}, \mathrm{z})))$ \& N(z)

In the derivation of DVRs from their nominal base we have to indicate the order by which the arguments are linked to syntactic arguments. This is indicated by the order of the lambda abstraction over the variables in the semantic form. The linking rule (43) of a FIGURE verb indicates that the nominal base $N$ is associated with the first argument of the predicate LOCATED (which is the argument place for the FIGURE), while the direct object is associated with the second argument (or the GROUND). Note that the argument $y$ of the base $N$ is bound by an existential quantifier indicating that the argument is not available in the syntax. Depending on the formalism, the existential quantifier can also be suppressed. The derivation of a GROUND verb (44) proceeds analogously, with the difference that the base noun $N$ is associated with the second argument of the predicate LOCATED, i.e., with the GROUND, and the direct object is associated with the first argument, or the FIGURE.

(43) Linking of FIGURE verbs to syntactic arguments (type: scremare) $\lambda \mathrm{N} \lambda \mathrm{z} \lambda \mathrm{x}$ ヨy [CAUSE (x, BECOME ( $\neg \operatorname{LOCATED}(\mathrm{y}, \mathrm{z}))) \& \mathrm{~N}(\mathrm{y})]$

(44) Linking of GROUND verbs to syntactic arguments (type: stanare) $\lambda \mathrm{N} \lambda \mathrm{y} \lambda \mathrm{x} \exists \mathrm{z}$ [CAUSE (x, BeCOME ( $\neg \operatorname{LOCATED}(\mathrm{y}, \mathrm{z}))) \& \mathrm{~N}(\mathrm{z})]$

An alternative representation ${ }^{20}$ (Kiparsky 1997: 484; Stiebels 1998: 272) uses two inverse predicates instead of our representation with one predicate and the reverse order of arguments. Locatum verbs (our FIGURE verbs) have the predicate Poss 'to have access to some object' (Stiebels 1998: 272), or HAVE-ON, HAVE-IN etc. (Kiparsky 1997: 484), as in (45). Location verbs (our GROUND verbs) are represented by a predicate LOC 'to be located somewhere' (Stiebels 1998: 272), or BE-IN, BE-ON, BE-AT (Kiparsky 1997: 484), as in (46).

(45) Locatum verbs / FIGURE verbs (type: scremare) $\lambda \mathrm{z} \lambda \mathrm{x} \exists \mathrm{z}$ [CAUSE (x, BeCOME $(\neg \operatorname{POSs}(\mathrm{y}, \mathrm{z}))) \& \mathrm{~N}(\mathrm{z})]$

(46) Location verbs / GROUND verbs (type: stanare) $\lambda \mathrm{z} \lambda \mathrm{x} \exists \mathrm{z}$ [CAUSE (x, BECOME ( $\neg$ LOC $(\mathrm{y}, \mathrm{z}))) \& \mathrm{~N}(\mathrm{z})]$

The difference between our representations (43) and (44) and the alternative representations (45) and (46) is mainly that in the latter representation the order of arguments for both classes of verbs is the same, while the arguments of the predicates are reversed. It is argued that only the lowest ranked argument can be realized by the base noun, as formulated in the 
Principle of Lexical Incorporation (Kiparsky 1997: 484; Stiebels 1998: 273). This assumption is a reflex of the syntactic approach to denominal verbs by Hale and Keyser (1992), which however is rejected by lexical approaches (cf. Kiparsky 1997; Stiebels 1998). Besides the syntactic considerations, we do not see further semantic or conceptual differences between a predicate LOC and its inverse POSS except that they have reverse arguments: $\operatorname{LOC}\left(\mathrm{y}_{\mathrm{FIG}}, \mathrm{z}_{\mathrm{GR}}\right)$ vs. POSS $\left(\mathrm{y}_{\mathrm{GR}}, \mathrm{z}_{\mathrm{FIG}}\right)$. It seems to us that they are inverse predicates and therefore it is a question of perspective, rather than of lexical semantic structure. Furthermore, checking the sample of DVRs in Italian in the appendix, we cannot see an advantage in using two predicates instead of one. Therefore, we prefer to express the reverse relation with one predicate, rather than with two.

\subsection{Representing the underspecification of DVRS}

The analysis leading to (43) and (44) is, however, not yet the solution we want, because it postulates two distinct semantic forms for a single morphological form. In this section, we propose an underspecified representation for the two subtypes of DVRs in Italian, which is shared by derived FIGURE and GROUND verbs. In the last subsection, we have demonstrated that the main difference between the representation of FIGURE verbs on the one hand, and GROUND verbs on the other, is the association of the base predicate with the FIGURE or the GROUND argument of the predicate LOCATED. Here we will propose two kinds of underspecified representations that account for that difference: (i) underspecification with a disjunction built in the particular form of the lexical representation, and (ii) underspecification with indexed variables and a condition on possible identifications of the indices.

Before discussing the two lexical representations, let us first present our views on underspecified representations in general. We represent the underspecification of a lexical item $\alpha$ for a feature $F$ with respect to the potential values $a$ or $b$ as exclusive disjunction $\vee$, as in (47):

(47) Schema of underspecified representation

The item $\alpha$ is underspecified for a feature $F$ with respect to the values $a$ or $b$ :

$\mathrm{F}(\mathrm{a}) \vee \mathrm{F}(\mathrm{b})$

In the first version of underspecification, the open part of the meaning may be expressed by a disjunction, i.e., by saying that the predicate of the base noun $N$ is applied to either the first or the second argument of the predicate LOCATED: 
(48) Underspecification I

CAUSE $(x, \operatorname{BECOME}(\neg \operatorname{LOCATED}(\mathrm{y}, \mathrm{z}))) \&[\mathrm{~N}(\mathrm{y}) \vee \mathrm{N}(\mathrm{z})]$

This representation correctly captures the observation that the derivational process can alternatively incorporate the FIGURE or the GROUND. The remaining argument is then realized as the direct object of the denominal verb. Additionally the representation reflects the observation that the necessity of choice between these two alternatives is part of the lexical semantics of the derivation. However, the representation would complicate the linking rules. We have one underspecified semantic representation, but two linking relations that differ in the binding of the arguments of the predicate LOCATED and the argument of the N.

(49) Linking of the underspecified representation

$\lambda \mathrm{y} \lambda \mathrm{x} \exists \mathrm{z}$ [CAUSE $(\mathrm{x}, \operatorname{BECOME}(\neg \operatorname{LOCATED}(\mathrm{y}, \mathrm{z}))) \&[\mathrm{~N}(\mathrm{y}) \vee \mathrm{N}(\mathrm{z})]]$

$\lambda \mathrm{z} \lambda \mathrm{x} \exists \mathrm{y}$ [CAUSe $(\mathrm{x}, \operatorname{BECOME}(\neg \operatorname{LOCATED}(\mathrm{y}, \mathrm{z}))) \&[\mathrm{~N}(\mathrm{y}) \vee \mathrm{N}(\mathrm{z})]]$

There are certainly different ways to overcome this formal problem. Manfred Bierwisch (p.c.) suggested the following solution that uses indexed variables and conditions on these indices. The variable $\mathrm{x}$ for the subject is fixed to the AGENT. The variable $\mathrm{y}_{\mathrm{j}}$ for the incorporated $\mathrm{N}$, and the variable $y_{i}$ for link to the direct object are not yet fixed to the two variables $\mathrm{y}_{\mathrm{k}}, \mathrm{y}_{1}$ standing for the arguments of the predicate LOCATED. The first argument of LOCATED must be of the concept type FIGURE, while the second of the concept type GROUND: $\operatorname{LOCATED}\left(\mathrm{y}_{\mathrm{FIG}}, \mathrm{y}_{\mathrm{GR}}\right)$. Only additional rules or conditions can identify these variables. For FIGURE verbs, the variable $\mathrm{y}_{\mathrm{j}}$ for the incorporated $\mathrm{N}$ is identified with the first argument $\mathrm{y}_{\mathrm{k}}$, and the variable $\mathrm{y}_{\mathrm{i}}$ for link to the direct object is identified with the second argument $y_{1}$. Alternatively, we can also identify the indices, as in (50). For GROUND verbs, we have to identify $\mathrm{j}$ with 1 (the incorporated $\mathrm{N}$ with the second argument of LOCATED) and $\mathrm{i}$ with $\mathrm{k}$ (the direct object with the first argument):

$$
\begin{aligned}
& \text { Underspecification II } \\
& \left.\lambda y_{\mathrm{i}} \lambda \mathrm{x} \exists \mathrm{y}_{\mathrm{j}} \text { [CAUSE }\left(\mathrm{x}, \operatorname{BECOME}\left(\neg \operatorname{LOCATED}\left(\mathrm{y}_{\mathrm{k}}, \mathrm{y}_{1}\right)\right)\right) \& \mathrm{~N}\left(\mathrm{y}_{\mathrm{j}}\right)\right] \\
& \text { with } \mathrm{j}=\mathrm{k} \text { and } \mathrm{i}=1 \text { (for FIGURE verbs) } \\
& \text { or } \mathrm{j}=1 \text { and } \mathrm{i}=\mathrm{k} \text { (for GROUND verbs) }
\end{aligned}
$$

This representation is more general and it allows for a variety of different identifications of the variables. Example (50) also allows for one semantic representation with one linking mechanism since the disjunction between two options is represented at a different level. However, it is not clear what determines the identification conditions at the second level. Therefore, we need independently motivated restrictions for the level of 
identification. Such a restriction is given by the conceptual properties of the base noun from which the denominal verb is derived.

\section{The resolution of underspecification}

As already stated above, a word with a vague meaning can be used in a sentence, but an underspecified meaning cannot be used. In order to fully derive the meanings of the DVRs, the underspecification must be decidable without access to the syntactic context. The hypothesis that we are going to propose is that the conceptual information associated with the base predicate $N$ suffices to resolve the underspecification. More specifically, we assume that the base nouns of the derivation come with a conceptual restriction, which is matched to the argument instantiations of the predicate LOCATED $\left(\mathrm{y}_{\mathrm{FIG}}, \mathrm{y}_{\mathrm{GR}}\right)$ :

In the preceding section we have developed an underspecified representation for the two types of DVRs in Italian. The representation uses index variables and conditions on indices that identify the variables. We have also noted that this representation is very powerful and therefore the conditions on the indices need a very strong restriction that is motivated by the conceptual structure of the base. We have already described the compositional interaction of the conceptual information of the base with the semantic information of the predicate LOCATED: If the base is a FIGURE concept, it is associated with the first argument of LOCATED in (50), and a GROUND concept is associated with the second argument, and vice versa. We now combine this observation with the flexible conditions on indices in (50) and replace the indices by the concept TYPES of the arguments according to the TYPES of the arguments of the predicate LOCATED $\left(\mathrm{y}_{\mathrm{FIG}}, \mathrm{y}_{\mathrm{GR}}\right)$, as in (51). The $\mathrm{j}$ index stands for the incorporated $\mathrm{N}$ and therefore for the type of DVR. If we identify the index $\mathrm{j}$ with the first or FIGURE argument, then we get a FIGURE verb, and the direct object can only be associated with the second or the GROUND argument, and vice versa: ${ }^{21}$

(51) Underspecification with concept-TYPE restrictions

$$
\begin{array}{ll}
\lambda y_{i} \lambda x \quad \exists y_{j} \text { [CAUSE }\left(x, \operatorname{BECOME}\left(\neg \operatorname{LOCATED}\left(\mathrm{y}_{\mathrm{FIG}}, \mathrm{y}_{\mathrm{GR}}\right)\right)\right) \& \mathrm{~N}\left(\mathrm{y}_{\mathrm{j}}\right) \text { ] } \\
\text { with } \mathrm{j}=\text { FIG and } \mathrm{i}=\mathrm{GR} \quad \text { (for FIGURE verbs) } \\
\text { or } \mathrm{j}=\text { GR and } \mathrm{i}=\mathrm{FIG} \quad \text { (for GROUND verbs) }
\end{array}
$$

The meaning of the FIGURE verb scremare is derived in the following way. It is assumed that the base predicate $\operatorname{CREMA}(\mathrm{y})$ is conceptually categorized as a FIGURE, which we indicate by the index on the argument of the base predicate: $\operatorname{CREMA}\left(\mathrm{y}_{\mathrm{FIG}}\right)$. Hence the instantiation of $\mathrm{N}\left(\mathrm{y}_{\mathrm{j}}\right)$ with $\operatorname{CREMA}\left(\mathrm{y}_{\mathrm{FIG}}\right)$ allows only for identifying the variable of the base noun 
with the first argument of $\operatorname{LOCATED}\left(\mathrm{y}_{\mathrm{FIG}}, \mathrm{y}_{\mathrm{GR}}\right)$. We can understand this process also as unification of the concept type of the arguments. Once the first argument is identified with the base noun, the second argument of $\operatorname{LOCATED}\left(\mathrm{y}_{\mathrm{FIG}}, \mathrm{y}_{\mathrm{GR}}\right)$ is free for linking with the direct object, which instantiates the GROUND in (52). As to the GROUND verb stanare, its nominal base, tana 'burrow', is conceptually categorized as a GROUND. Therefore, the base is instantiated by TANA $\left(\mathrm{y}_{\mathrm{GR}}\right)$, which occupies the second argument of LOCATED $\left(\mathrm{y}_{\mathrm{FIG}}, \mathrm{y}_{\mathrm{GR}}\right)$ and binds the GROUND. Therefore, the only available argument is the FIGURE argument that is linked to the direct object.

(52) Resolving the underspecification of a FIGURE verb (scremare) $\lambda \mathrm{y}_{\mathrm{i}} \lambda \mathrm{x} \exists \mathrm{y}_{\mathrm{j}}$ [CAUSE (x, BECOME $\left.\left.\left(\neg \operatorname{LOCATED}\left(\mathrm{y}_{\mathrm{FIG}}, \mathrm{y}_{\mathrm{GR}}\right)\right)\right) \& \operatorname{CREMA}\left(\mathrm{y}_{\mathrm{FIG}}\right)\right]$ $\lambda \mathrm{y}_{\mathrm{GR}} \lambda \mathrm{x} \exists \mathrm{y}_{\mathrm{FIG}}\left[\operatorname{CAUSE}\left(\mathrm{x}, \operatorname{BECOME}\left(\neg \operatorname{LOCATED}\left(\mathrm{y}_{\mathrm{FIG}}, \mathrm{y}_{\mathrm{GR}}\right)\right)\right) \&\right.$ $\left.\operatorname{CREMA}\left(\mathrm{y}_{\mathrm{FIG}}\right)\right]$

(53) Resolving the underspecification of a GROUND verb (stanare) $\lambda \mathrm{y}_{\mathrm{i}} \lambda \mathrm{x} \exists \mathrm{y}_{\mathrm{j}}$ [CAUSE ( $\left.\left.\mathrm{x}, \operatorname{BECOME}\left(\neg \operatorname{LOCATED}\left(\mathrm{y}_{\mathrm{FIG}}, \mathrm{y}_{\mathrm{GR}}\right)\right)\right) \& \mathrm{~N}\left(\mathrm{y}_{\mathrm{j}}\right)\right]$ $\lambda \mathrm{y}_{\mathrm{FIG}} \lambda \mathrm{x} \exists \mathrm{y}_{\mathrm{GR}}\left[\operatorname{CAUSE}\left(\mathrm{x}, \operatorname{BECOME}\left(\neg \operatorname{LOCATED}\left(\mathrm{y}_{\mathrm{FIG}}, \mathrm{y}_{\mathrm{GR}}\right)\right)\right) \&\right.$ $\left.\operatorname{TANA}\left(\mathrm{y}_{\mathrm{GR}}\right)\right]$

The two types of DVRs in Italian can be best represented by the underspecified representation (51). This representation shows the interaction between the conceptual structure, the semantic form, and the linking to syntactic arguments. Furthermore, it makes it possible to derive FIGURE verbs or GROUND verbs, depending on the conceptual properties of the base noun. Other theories have claimed the importance of the conceptual feature for the derivation process, but were unable to show the interaction of conceptual information and semantic information in the derivation process.

\subsection{Other kinds of base nouns}

Notice that the matching relationships between conceptual categories for nouns and the FIGURE vs. GROUND dichotomy comprise far more categories than those we have mentioned until now, i.e., SUBSTANCE, CONTAINER, PLACE, BODY PART, etc.

Furthermore, some nouns, as we have seen (example [36]), are associated with alternative conceptualizations. Thus carta 'paper' may be categorized as both, PART (OF) or CONTAINER. Hence a verb may be derived as both, a FIGURE verb or a GROUND verb; accordingly, scartare may be translated as 'take the paper away from $X$ ' or 'take $X$ out of the paper' - but not both together. In a given sentence, scartare can take only one of the two possible meanings. 
This approach also explains those cases in which a nominal base fails to produce an acceptable DVR, such as piede 'foot'. Spedare is fine from the formal point of view, but one does not know what it might mean, and the explanation is that 'foot' does not carry a conceptual category that could be mapped onto FIGURE or GROUND. In fact, there is no typical situation in which something is put into or removed from a foot.

\section{Conclusion}

In the process of writing this article, we have tried to achieve a better understanding of one specific pattern of Italian word formation, proposing a rule that operates on meaning as well as on form, and where the interplay of grammar and cognition is specified on the basis of semantic underspecification. This approach, which took us beyond the scope of descriptive Italian linguistics, implies a stronger hypothesis than the treatment in terms of mere ambiguity, proposed in the literature on similar word formation patterns in other languages. We have shown that it is possible to account for a case of systematic meaning alternation by just one unitary rule of grammar, constrained by conceptual information. We have been able to do so by adapting to morphology and semantics a notion that originally was used in phonology, the notion of underspecified representation.

Our data also seem to point to interesting typological facts. Some languages, such as English, create affixless denominal verbs very freely, leaving a large amount of constraints to the conceptual level. Other languages, e.g., Italian, prefer affixation, reducing (but, of course, not abolishing) the space of conceptual constraints. It would be interesting to elaborate this aspect.

Received 11 October 2002

Revised version received

University of Stuttgart

6 September 2004

University of Constance

\section{Appendix: a sample of lexicalized DVRs}

The following list contains lexically stored DVRs. ${ }^{22}$ It has been extracted from: a. the present article; b. De Mauro and Moroni (1996), a corpus-based dictionary of the essential vocabulary; c. the basic layer of the DISC (Sabatini and Coletti 1997), ${ }^{23}$ and; d. Iacobini (2004). The verbs are given in their citation form, the infinitive, although some of them, e.g., scremare, are only strongly lexicalized as adjectives derived from participles (latte scremato 'low-fat milk'). For each verb the base noun is added and English translations are given. 
Table 1. A sample of lexicalized DVRs

\begin{tabular}{|c|c|}
\hline sbandare to skid; banda band, strip. & $G$ \\
\hline sbarbare to shave; barba beard. & $F$ \\
\hline sbarcare to unload, to disembark; barca boat. & $G$ \\
\hline sbavarel to dribble baval saliva, dribble. & $F$ \\
\hline sbavare 2 to clean a welding seam; bava2 silk filament. & $F$ \\
\hline sbeccare to chip; becco beak, spout. & $F$ \\
\hline sboccare to flow out into, to lead out into; bocca mouth. & $G$ \\
\hline sbramare to satisfy someone's longing; brama longing, yearning. & $F$ \\
\hline sbrinare to defrost; brina frost. & $F$ \\
\hline sbucare to remove from a hole. buco, buca hole. & $G$ \\
\hline sbucciare to peel, to shell; buccia peel, shell. & $F$ \\
\hline scagionare to exonerate, free from blame; cagione (archaic) cause. & $F$ \\
\hline scapare to remove the head; capo head. & $F$ \\
\hline scarcerare to release (from prison); carcere prison. & $G$ \\
\hline scardinare to take off its hinges; cardine hinge. & $G$ \\
\hline scartare to unwrap; to take off the paper; carta paper. & $F G$ \\
\hline scatenare to unchain; to trigger off; catena chain. & $F G$ \\
\hline schiesare to cancel the quality of being a church; chiesa church. & $F$ \\
\hline scolpare to free from blame, exonerate; colpa guilt. & $F$ \\
\hline scoraggiare to discourage; coraggio courage. & $F$ \\
\hline scostolare to remove the ribs; costola rib. & $F$ \\
\hline scremare to skim; crema cream. & $F$ \\
\hline scrostare to scrape off, strip (off); crosta crust, scab. & $F$ \\
\hline sdebitare to rid of a debt; debito debt. & $F$ \\
\hline sdoganare to clear through customs; dogana customs. & $G$ \\
\hline sdottorare to deprive someone of the title of doctor; dottore doctor. & $F$ \\
\hline sdrogare to free from drug addiction, to detoxify; droga drug. & $F$ \\
\hline
\end{tabular}


Table 1 (Continued)

\begin{tabular}{|c|c|}
\hline sfamare to satisfy someone's hunger; fame hunger. & $F$ \\
\hline sfasciare to unbandage; fascia strip, bandage. & $F$ \\
\hline $\begin{array}{l}\text { sfilare pull the threads out of, to unstring; to take from a string; filo string, thread, } \\
\text { yarn. }\end{array}$ & $F G$ \\
\hline sfoderarel to take out (of the sheath); fodero sheath. & $G$ \\
\hline sfoderare 2 to remove the lining or dust jacket; fodera lining, dust jacket. & $F$ \\
\hline sfogliare to pluck the petals off; foglia leaf. & $F$ \\
\hline sfollare to evacuate; folla crowd. & $F$ \\
\hline sfornare to take out of the oven; forno oven. & $G$ \\
\hline sfrattare to evict; fratta (archaic) shelter. & $G$ \\
\hline sfregiare to slash, to gash; fregio (archaic) decoration, ornament. & $F$ \\
\hline sganciare to unhook, to unfasten; gancio hook. & $G$ \\
\hline sgrassare to remove the grease from; grasso fat, grease. & $F$ \\
\hline sguainare to draw, unsheathe (a weapon); guaina sheath. & $G$ \\
\hline sgusciare to remove the shell, to take out of the shell; guscio shell. & $F G$ \\
\hline slogare to sprain, to dislocate; luogo place. & $G$ \\
\hline sloggiare to drive out; alloggio accommodation, lodging. & $G$ \\
\hline smacchiare to remove stains from; macchia mark, spot. & $F$ \\
\hline smascherare to unmask; maschera mask. & $F$ \\
\hline snaturare to distort, misrepresent; natura nature. & $F$ \\
\hline snidare to drive out, to find; nido nest. & $G$ \\
\hline snocciolare to stone, to shell out; nocciolo stone (of a fruit). & $F$ \\
\hline snodare to untie, to undo (a knot); nodo knot. & $F$ \\
\hline spellare to skin; pelle skin. & $F$ \\
\hline spennare to pluck; penna feather. & $F$ \\
\hline spodestare to depose, dethrone; podestà power, authority. & $F$ \\
\hline spolverare to clear of dust; polvere dust. & $F$ \\
\hline
\end{tabular}


Table 1 (Continued)

\begin{tabular}{|l|l|}
\hline spostare to move, to shift; posto place. & $G$ \\
\hline spuntare to break the point of, to trim; punta point. & $F$ \\
\hline sradicare to uproot, to root out; radice root. & $F$ \\
\hline stanare to drive out; tana lair, den, burrow. & $G$ \\
\hline stappare to uncork, to uncap; tappo cork, cap. & $F$ \\
\hline stonare to sing, play out of tune; tono tone. & $G$ \\
\hline svasare to remove from the pot, to repot; vaso vase, pot. & $G$ \\
\hline svelare to reveal, to uncover; velo veil. & $F$ \\
\hline sverginare to deflower; vergine virgin. & $F$ \\
\hline sviare to lead astray; via road, way, street. & $G$ \\
\hline svitare to unscrew; vite screw. & $F$ \\
\hline
\end{tabular}

\section{Notes}

1. Earlier versions of this article were presented at the Workshop on Verbs, Arguments, and Polysemy, Konstanz, SFB 471, July, 23-25, 2001, at the Conference on Predicative Morphosyntax: Parameters of Variation in Romance, Palermo, November, 22-24, 2001, at the Berkeley Linguistics Colloquium, April, 1, 2002, and at the Conference Zwischen Laut und Sinn, Düsseldorf, June, 28, 2002. We wish to thank the audiences at these occasions for constructive comments and suggestions, and in particular Patrick Farrell for detailed comments, as well as Bernard Fradin and Françoise Kerleroux for a long discussion on this issue. Manfred Bierwisch gave us very valuable comments on a previous version of the article, which helped us very much to clarify the presentation of our ideas. We are also grateful to two anonymous reviewers to whom we owe considerable improvements of the version we submitted to Linguistics in 2002. The research was supported by a Heisenberg fellowship for the first author and for the second by the DFG-funded Sonderforschungsbereich 471 "Variation and Evolution in the Lexicon". Correspondence address: Klaus von Heusinger, Institut für Linguistik/ Germanistik, Universität Stuttgart, Postfach 1060 37, 70049 Stuttgart, Germany.

2. This distinction between the two subclasses of DVRs corresponds to the contrast between LOCATUM verbs (= FIGURE verbs) and LOCATION verbs (= GROUND verbs) of Clark and Clark (1979: 770-773).

(i) LOCATUM verbs: skin (the rabbit) 'remove the skin from $\mathrm{X}$ ' bone (the fish) 'remove the bones from X'

(ii) LOCATION verbs: mine (the gold) 'remove $\mathrm{X}$ from a mine' pod (the pear) 'remove X from the pods' 
This terminology is also used by other authors, e.g., Kiparsky (1997), Wunderlich (1997). The alternative terminology we are using goes back to Talmy (1985), who introduced FIGURE, GROUND, PATH and MANNER as basic concepts of motion events. See Section 4.1 for further discussion.

3. The assumption that morphological segments are stored in the lexicon is controversial, but the general discussion on morphological representation is immaterial to the aims of this study.

4. The notation is shorthand for the relationships defined by the Lexical Mapping Theory (LMT) (Bresnan 2001: 302-311). Since our presumed readers probably are more familiar with a linking mechanism based upon lambda-abstracted lexical representations, LMT will not be applied in this article.

5. Lower case letters refer to the morphological level: $v$ is the category of lexical verbs. In order to become syntactic words, i.e., forms which are accepted by syntax, they need to undergo appropriate processes of inflectional morphology. (Throughout this article, only lexical words are represented).

6. A nice example can be found in the Italian writer Tiziano Scarpa's book Venezia è un pesce. Scarpa describes a situation where a cat is taking a rest on the outer sill (It. $b a$ laustra) of a window in the fifth storey and is shoved off from there and flung down into the street as her master, unaware of the situation, pushes the shutter open: il gatto è sbalaustrato, 'the cat is pushed off the balustrade'. It can safely be assumed that no one has ever used this verb before.

7. Kiparsky (1997: 482) points out with respect to English "putting" verbs that the locative phrase governed by the preposition does not need to be and actually rarely is the noun from which the verb was derived. There is a well defined conceptual constraint, in Kiparsky's words: "If an action is named after a thing, it involves a canonical use of the thing." His generalization also holds for Italian; cf. the following uses of stanare, found on the Internet: stanare da una casa 'to drive out from a house', stanare da una cantina 'to drive out from a cellar', stanare da qualche angolo della casa 'to drive out from some corner of the house', stanare da un buco 'to drive out from a hole', stanare da un nascondiglio 'to drive out from a hiding place', stanare da un polveroso archivio 'to extract from a dusty archive', stanare da nicchie biologiche 'to chase from biological niches', stanare da sotto $i$ letti 'to drive out from under the beds', stanare da sotto le automobili 'to drive out from under the automobiles', stanare da li dentro 'to drive out from in there'. The relationship that licenses these obliques is the conceptualization of a tana 'burrow, den' as a place that functions as a shelter from perception and access.

8. Kiparsky (1997: 479) gives lists of (unprefixed) English FIGURE ("Locatum") and GROUND ("Location") verbs. The FIGURE verbs are 149, the GROUND verbs only are 73. For lists of English affixless denominal verbs of location, see also Clark and Clark (1979: 770-773) and Levin (1993: 96-98, 120-123).

9. Another possibility would be to first add the prefix to a noun and then derive the DVR from that prefixed noun. Actually, there are a few nouns with "negative" $s$-: favore 'favor' $\rightarrow$ sfavore 'disfavor', vantaggio 'advantage' $\rightarrow$ svantaggio 'disadvantage'. But that morphological relationship is not productive at all, and it has never occurred to anyone to suggest such a treatment of DVRs. - Notice that there are quite a few adjectives with "negative" $s$-: comodo 'comfortable' $\rightarrow$ scomodo 'uncomfortable', piacevole 'pleasant' $\rightarrow$ spiacevole 'unpleasant'. We do not discuss them in this article, because they deserve an analysis in their own right.

10. If one assumes Aronoff's unique base hypothesis, the alternative is slightly different: i. If we suppose that $/ \mathrm{s} /$ is the same prefix in sconnettere and scremare, then the longer 
chain of derivation follows with necessity. ii. If we suppose that /s/ is the phonological exponent of two different prefixes, then the alternative remains unresolved. So the alternative as such does not depend on the assumption of the unique base hypothesis. (We do consider prefix $s$ - as identical in deverbal and denominal verbs, but, on the other hand, we think that the unique base hypothesis concerns a principle that can be violated; It. $s$ - seems to be a typical case of such a violation.)

11. A count made in the Appendix confirms the preference of Italian for prefixed "putting" verbs. Among the 64 DVRs listed there, only 18 have a lexicalized unprefixed counterpart with a "putting" semantics, two of which are marked as "uncommon" in Sabatini and Coletti (1997).

12. We are using an explicit formalism not only for the semantics, but also for the morphological structures, in which the semantics is embedded. We do so in order to emphasize that we are analyzing a specific aspect of the grammar of a specific language, not just some vague conceptual variation. We chose the LFG-based model because we think that it expresses quite nicely the interplay between the formal processes of word formation and the information these processes make available for the level of the sentence. We hope that those readers who reject the assumption of morphological constituency will be able to easily translate the notations into their preferred formalism.

13. There is no derivational suffix in the derived verbs; the /a/ of stanare etc. is a stem extension, which requires that the root already be a verb.

14. Notice that the rule overgenerates, inasmuch as the class of prefixes needs to be narrowed down. Among the strongly productive verb prefixes only $s$ - and in- (imburrare 'to butter') fit to the rule, whereas ri- 'again' does not occur in denominal verbs. As far as we know, an explicit morphology of denominal Italian verbs remains to be elaborated.

15. One reviewer observed "that the classification of SUBSTANCE as FIGURE is rather controversial" as is illustrated by both uses of water in water in the boat vs. the boat on the water, which is also reflected in two German denominal verbs: the GROUND verb wassern 'alight on water' and the FIGURE verb wässern 'water, irrigate'. We think that this is an exception or a different conceptualization of water as PLACE. It is interesting to note that there is only one reversative verb entwässern 'drain'. Compare the German reversative verbs enteisen, 'de-ice', entgasen 'degas', entgiften 'detox', entkalken 'decalcify' etc.

16. Cf. Clark and Clark (1979: 793), who note with respect to the conceptualization of English denominal verbs: "Some concrete objects have predominant features that lead to a remarkable type of ambiguity. Two predominant features in the generic theory [i.e., conceptual structure, Ch. S. and K. v. H.], for 'milk', for example, are that milk is a substance put into or onto certain foods (its potential roles) and that it is a substance extracted from the mammary glands (its ontogeny). Consequently, milk, has developed two meanings. In milk the tea it means 'put milk in'; in milk the cow it means 'take milk out'."

17. Manfred Bierwisch (p.c.) suggested this representation to us. It replaces our earlier form (i) in which the change of situations is explicitly stated, with an initial state $s_{1}$, in which an entity $y$ is located in or with (on, around etc.) an entity $z$; a subsequent state $s_{2}$, in which $y$ is no longer located in or with $z$; and an entity $x$, typically a person, which causes $s_{1}$ to change into $s_{2}$.

(i) $\operatorname{Cause}\left(\mathrm{x}, \operatorname{CHANGe}\left(\mathrm{s}_{1}, \mathrm{~s}_{2}\right) \& \mathrm{~s}_{1}=\operatorname{Located}(\mathrm{y}, \mathrm{z}) \& \mathrm{~s}_{2}=\neg \operatorname{Located}(\mathrm{y}, \mathrm{z})\right)$

18. (38) represents a particular instantiation of a the more general form (i) for "reversative verbs" (Stiebels 1997: 170) with $P$ as a variable over different predicates. See Stiebels 
(1997: 170-186) for further discussion of conceptual restrictions of the use of such reversative verbs:

(i) CAUSE (x, BECOME $(\neg \mathrm{P}(\mathrm{y})))(\mathrm{s})$.

19. The entry does not account for the phonological restrictions to the base: the base must not begin with a vowel or with a sibilant; in these cases suppletion is possible with disor de- (Iacobini, 2004, Section 3.6.4). - We do not discuss the relationship between the prefixes of DVRs and the $s$ - which is prefixed to verbs, nor do we treat the homonymous $s$-, which appears in verbs like sferragliare 'to rattle', from ferraglia 'scrap iron'.

20. We owe our thanks to a reviewer who asked us to clarify this point and suggested some relevant references.

21. The idea to use sortal restrictions on arguments (or variables) for representing conceptual information was first suggested in von Heusinger (2002: 18). Plag (1998) suggests a similar approach towards the lexical representation of the polysemy of -ize derivatives in English. Plag (1998: 232) accounts for the different patterns in one lexical representation (i) (= (20) in Plag 1998), where the argument frame as well as the thematic structure has different options, as indicated e.g., by the alternation of Theme/Base vs. Base/ Theme. However, it is not clear how these options are restricted or determined.

(i) LCS of -ize verbs (generalized)

[[ ]BASE $-i z e] \mathrm{v}$

$\left\{\mathrm{NP}_{\mathrm{i}} \_\mathrm{NP}_{\text {Theme }}, \mathrm{NP}_{\text {Theme }} \longrightarrow, \mathrm{NP}_{\mathrm{i}} \longrightarrow\right\}$

$\operatorname{CAUSE}\left([\mathrm{i}, \mathrm{i} \text {, GO ([Property, Thing }]_{\text {Theme/Base }}\right.$; $\left.\left.\left.\left.[\text { TO ([Property, Thing }]_{\text {Base/Theme }}\right]\right)\right]\right)$

22. Some DVRs seem to be lexicalized only as adjectives, derived from participles, e.g., sfrenato 'wild, uncontrolled' from freno 'brake, restraint' smodato 'unrestrained', from modo 'mesure' (archaic in that meaning); spensierato 'carefree, lighthearted', from pensiero 'thought, sorrow'; spudorato 'shameless', from pudore 'shame'; svogliato 'listless, lazy, indolent', from voglia 'wish, desire'. They are not in the list. We have also excluded those DVRs which are hardly transparent to the untrained speaker, or where its root differs from the correspondent noun, such as sbiadire 'to bleach', from Old It. biado 'color'; spalancare 'to open wide', from Old It. palanca 'lock'; intransitive sgusciare 'to slip out, to wriggle out', where the nominal concept (guscio 'shell') has almost completely bleached out.

23. This basic layer (DISC base) is a choice of ca. 10.000 entries that the authors of the dictionary think to be most likely to be known and available to the speakers (lemmi ritenuti più probabilmente conosciuti e quindi "disponibili", Sabatini and Coletti (1997), in the booklet that goes with the compact disc version, p. 16).

\section{References}

Bierwisch, Manfred (1982). Formal and lexical semantics. Linguistische Berichte 80, 3-17.

- (1983). Semantische und konzeptuelle Repräsentation lexikalischer Einheiten. In Untersuchungen zur Semantik, R. Ruzicka and W. Motsch (eds.), 61-89. Berlin: Akademie Verlag.

— and Bosch, Peter (eds.) (1995). Semantic and Conceptual Knowledge. Bericht Nr. 71. Stuttgart and Tübingen: SFB 340 and IBM Deutschland.

Bresnan, Joan (2001). Lexical-Functional Syntax. Malden, MA and Oxford, UK: Blackwell. 
Clark, Eve V. and Clark, Herbert H. (1979). When nouns surface as verbs. Language 55, 767-811.

De Mauro, Tullio and Moroni, G. G. (1996). DIB - Dizionario di base della lingua italiana. Turin: Paravia.

Hale, Kenneth and Keyser, Samuel (1992). The syntactic character of thematic structure. In Thematic Structure: Its Role in Grammar, I. M. Roca (ed.), 107-143. Berlin and New York: Foris.

von Heusinger, Klaus (2002). Italian nominalization of -ata: derivation and the structure of the lexicon. Arbeitspapier 109. Department of Linguistics, Universität Konstanz.

Iacobini, Claudio (2004). Prefissazione. In La formazione delle parole in italiano, M. Grossmann and F. Rainer (eds.), 97-163. Tübingen: Niemeyer.

Kiparsky, Paul (1997). Remarks on denominal verbs. In Complex Predicates, A. Alsina, J. Bresnan, and P. Sells (eds.), 473-499. Stanford: CSLI.

Levin, Beth (1993). English Verb Classes and Alternations. A Preliminary Investigation. Chicago and London: University of Chicago Press.

Mayo, Bruce (1999). A computational model of derivational morphology. Unpublished doctoral dissertation, University of Hamburg.

—; Schepping, Marie-Theres; Schwarze, Christoph; and Zaffanella, Angela (1995). Semantics in the derivational morphology of Italian: implications for the structure of the lexicon. Linguistics 33, 883-983.

Pause, Peter E.; Botz, Achim; and Egg, Markus (1995). Partir c'est quitter un peu - a twolevel approach to polysemy. In Lexical Knowledge in the Organization of Language, U. Egli, P. Pause, C. Schwarze, A. von Stechow, and G. Wienold (eds.), 245-282. Amsterdam: Benjamins.

Plag, Ingo (1998). The Polysemy of -ize derivatives: on the role of semantics in word formation. In Yearbook of Morphology 1997, Geert Booij and Jaap van Marle (eds.), 219-242. Dordrecht: Kluwer.

Sabatini, Francesco and Coletti, Vittorio (1997). DISC: Dizionario Italiano Sabatini Coletti. CD-ROM, version 1.1. Florence: Giunti Multimedia.

Schwarze, Christoph (1995). Semantic and conceptual structures in word formation. In Semantic and Conceptual Knowledge, M. Bierwisch and P. Bosch (eds.), 211-221. Bericht Nr. 71. Tübingen and Stuttgart: SFB 340 and IBM Deutschland.

-(1999). Lexical-functional morphology and the structure of the lexicon. In Boundaries of Morphology and Syntax, L. Mereu (ed.), 73-95. Amsterdam: Benjamins.

- and Schepping, Marie-Theres (1995). Polysemy in a two-level semantics. In Lexical Knowledge in the Organization of Language, U. Egli, P. Pause, C. Schwarze, A. von Stechow, and G. Wienold (eds.), 283-300. Amsterdam; Philadelphia: Benjamins.

Stiebels, Barbara (1997). Lexikalische Argumente und Adjunkte: Zum semantischen Beitrag von verbalen Präfixen und Partikeln. Studia Grammatica 39. Berlin: Akademie Verlag.

- (1998). Complex denominal verbs in German and the morphology-semantics interface. In Yearbook of Morphology 1997, G. Booij and J. van Marle (eds.), 265-302. Dordrecht: Kluwer.

- and Wunderlich, Dieter (1995). Morphology feeds syntax: The case of particle verbs. Linguistics 32, 913-969.

Talmy, Leonard (1985). Lexicalization patterns: semantic structure in lexical forms. In Language Typology and Syntactic Description, T. Shopen (ed.), vol. 3, 57-149. Cambridge: Cambridge University Press.

Wunderlich, Dieter (1997). CAUSE and the structure of verbs. Linguistic Inquiry 28, 27-68. 